DOI - https://doi.org/10.5965/2316796309182020078

\title{
PERCEPÇÃO DE USO E ANTROPOMETRIA DO PÉ NO DESIGN DE CALÇADOS PARA ASAÚDE
}

\section{FOOTWEAR USE PERCEPTION AND FOOT ANTHROPOMETRY FOR HEALTH FOOTWEAR DESIGN}

Leticia Takayama $^{1}$

Giselle Schmidt Alves Diaz Merino ${ }^{2}$ 


\section{Resumo}

O estudo teve como objetivo apresentar - resultado de uma coleta de dados que averiguou questões relacionadas a percepção de uso do calçado e a antropometria dos pés. A amostra foi composta de 14 participantes do sexo feminino. No levantamento sobre a percepção de uso dos calçados, foi aplicado um questionário com antropometria foi realizada a medição do comprimento (numeração) do pé e perímetro do metatarso. Como resultado, - estudo contribuiu para investigar de modo preliminar algumas questões relacionadas a percepção de uso do calçado, a saúde dos pés e a comparação entre as medidas antropométricas com a norma de dimensionamento de calçados no Brasil.

Palavras-chave: Design de Calçado; Saúde Ergonomia; Antropometria.

\section{Abstract}

The study aimed to present the results of a survey that investigated the relation of footwear use perception and foot anthropometry. The data was collected with 14 female participants. The survey about the perception of footwear use was applied in a questionnaire with 14 questions. The anthropometric survey measured the length (size) of the foot and the metatarsal girth. As a result, the study contributed to investigate in a preliminary way some questions about footwear use perception, foot health and the comparison between the anthropometric measures and the regulation of footwear dimensions in Brazil.

Key-words: Footwear Design; Health; Ergonomics; Anthropometry.

\section{INTRODUÇÃO}

O desenvolvimento de calçados ergonômicos e confortáveis depende do estudo antropométrico dos pés dos usuários (XIONG; ZHAO, 2013). Segundo Schmidt (1995), o calçado que apresenta condições saudáveis de uso deve possuir o formato anatômico dos pés, elaborada por meio do desenvolvimento de fôrmas e modelos mais adequados.

No entanto, a produção dos calçados é feita com base em sistemas de medidas que padronizam o seu tamanho conforme o comprimento e perímetro dos pés (SCHMIDT, 1995; LIGER, 2015). No Brasil, o sistema utilizado é o ponto francês, desenvolvido em Paris, que utiliza o valor de dois terços de $1 \mathrm{~cm}$ como 1 ponto da numeração em relação ao comprimento dos pés e a variação de $0,5 \mathrm{~cm}$ no perímetro dos metatarsos entre uma numeração e outra (SCHMIDT, 1995; LIGER, 2015).

A NBR 15159:2013, norma vigente no Brasil que regulamenta o conforto de calçados e componentes com base no ponto francês, é baseada em medidas europeias e pode apresentar diferenças dimensionais em relação ao perfil dos pés brasileiros (DOMINGUES, 2016). Segundo Manfio (1995), a utilização de um sistema de medidas baseado em dados europeus, nesse caso francês, pode causar problemas de saúde como deformidades e prejudicar o funcionamento corporal, uma vez que não foi desenvolvido com base em dados antropométricos dos pés brasileiros.

Desse modo, o presente estudo tem como objetivo apresentar o resultado de uma coleta de dados que averiguou questões relacionadas a percepção de uso do calçado e a antropometria dos pés. O estudo limita-se ao entendimento das percepções das participantes da amostra por meio de um questionário com perguntas sobre o uso do calçado. Do mesmo modo, o estudo também contempla a coleta de dados antropométricos dos pés para verificar diferenças em relação à numeração e dimensão de perímetro da região metatarso-falangeana do pé em comparação com a norma NBR 15159:2013.

\section{PROCEDIMENTOS METODOLÓGICOS}

O estudo apresenta natureza aplicada, objetivos exploratórios e abordagem qualitativa e quantitativa (SILVA; MENEZES, 2005). A natureza está relacionada à geração de conhecimentos novos para a aplicação prática de melhorias no dimensionamento dos calçados pelo levantamento antropométrico. Os objetivos exploratórios pretendem dar maior familiaridade com o problema do estudo por meio dos procedimentos de pesquisas bibliográficas para a fundamentação teórica, levantamento de dados demográficos sobre a percepção de uso do calçado e levantamento das dimensões antropométricas dos pés, apresentando uma abordagem qualitativa e quantitativa, respectivamente.

O estudo foi dividido em duas etapas: Etapa 1 - Fundamentação Teórica e Etapa 2 - Coleta de Dados. Na Etapa 1 - Fundamentação Teórica foi elaborada uma revisão de literatura nos três temas: Calçado, Anatomia do Pé, Ergonomia e Antropometria do Pé. As buscas para a Fundamentação Teórica foram feitas na língua portuguesa e inglesa em livros, bases de dados da literatura como Scopus e Web of Science e na Biblioteca Digital Brasileira de Teses e Dissertações (BDTD). Para o tema Calçado foram utilizados os termos em português/inglês: sistema de numeração/size system; calçado/footwear, usuário/user, e ajuste/fit com o intuito de entender o conteúdo sobre os calçados, a sua percepção de uso e os desafios em relação à adequação do seu
${ }^{1}$ Mestra - UFSC (takayamaleticia@gmail.com)

2 Doutora - UFSC (gisellemerino@gmail.com)
ISSN: 2316-7963 
dimensionamento com os pés. Na pesquisa sobre Anatomia do Pé foram utilizadas as palavras: pé/foot, anatomia/anatomy e estrutura/structure para compreender a estrutura dos pés e as nomenclaturas necessárias para a descrição científica das partes relacionadas ao estudo. Na sequência, o tema Ergonomia e Antropometria do partes relacionadas ao estudo. Na sequência, o tema Ergonomia e Antropometria do
Pé foi pesquisado com as palavras: ergonomia/ergonomics/human factors, pé/foot, antropometria/ anthropometry, dados/data e medida/measurement para entender conceitos e procedimentos para o levantamento antropométrico.

Na Etapa 2 - Coleta de Dados, foram abordados o levantamento sobre a percepção de uso do calçado, antropometria dos pés e análise dos dados. A coleta ocorreu entre os dias 20 e 21 de setembro de 2018 no pátio da Universidade do Sagrado Coração, em Bauru - SP, durante a realização do II CBTA: Congresso Brasileiro de Pesquisa e Desenvolvimento em Tecnologia Assistiva: Engenharia e Design, evento que contou com a participação de 505 pessoas. A coleta de dados foi realizada durante o tempo de intervalo (30 minutos) da programação no dia 20 de setembro e horário de almoço (1 hora e 30 minutos) no dia 21 de setembro.

Para o presente estudo, foram selecionados dados da população feminina, uma vez que esta pode apresentar dimensões anatômicas e percepções de uso do calçado diferenciadas da população masculina. A amostra não probabilística por conveniência foi composta de 14 participantes do sexo feminino, totalizando o levantamento antropométrico das dimensões de 28 pés (pé direito e pé esquerdo das participantes). Quanto aos aspectos éticos, foi utilizado o Termo de Consentimento Livre e Esclarecido e Termo de Consentimento de Uso de Imagem e Voz, devidamente assinados pelas participantes que concordaram participar da amostra como voluntárias, de forma anônima e confidencial.

O roteiro da coleta de dados (Figura 1) envolveu os seguintes passos: assinatura do Termo de Consentimento Livre e Esclarecido e Termo de Consentimento de Uso de Imagem e Voz; preenchimento do Questionário de Percepção de Uso do Calçado; verificação da numeração do pé direito pela régua de medição; medição do perímetro do metatarso do pé direito com a fita métrica, localizado na articulação metatarsofalangeana; verificação da numeração do pé esquerdo pela régua de medição; e medição do perímetro do metatarso do pé esquerdo com a fita métrica.

Figura 1: Roteiro da coleta de dados

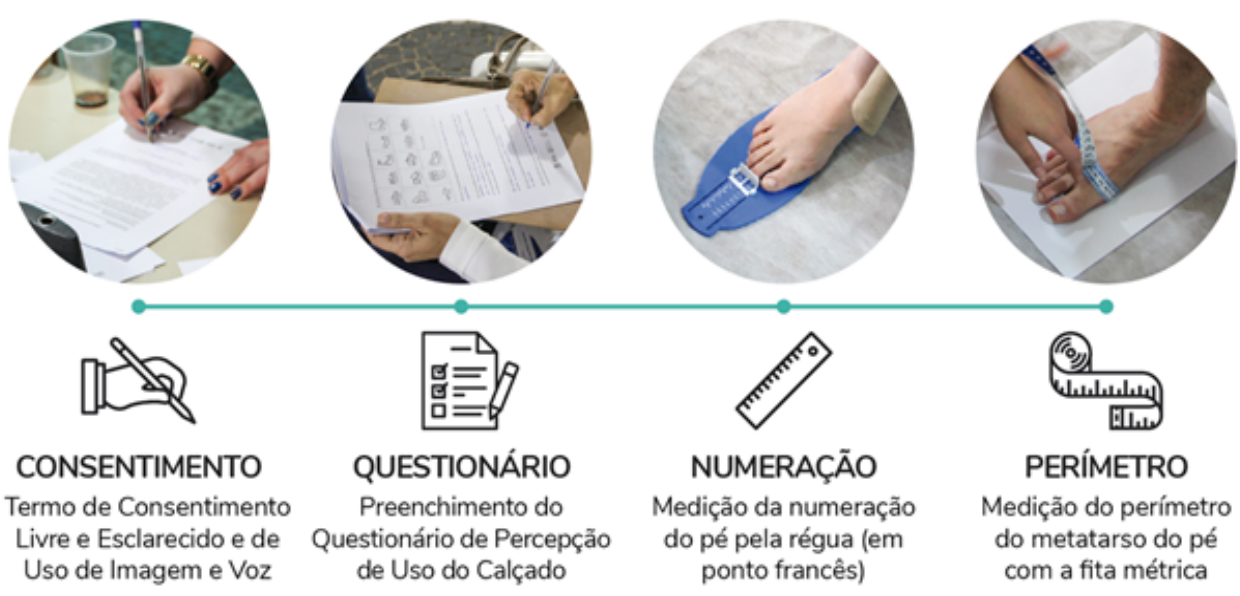

Fonte: Os autores
As participantes foram solicitadas a preencher um Questionário de Percepção de Uso do Calçado composto de 14 perguntas abertas e fechadas com base em Manfio (1995) e Menin (2009) divididas em tópicos sobre a identificação das participantes ( 1 - sexo, 2 - idade, 3 - cidade/estado, 4 - descendência e 5 - problemas de saúde) e percepção de uso do calçado (6 - número do calçado que mais usa, 7 - sentimento de desconforto em regiões dos pés, 8 - modelos de calçado que mais usa, 9 - modelos de calçado que sente mais conforto, 10 - modelos de calçado que sente mais desconforto, 11 - frequência do uso de salto alto, 12 - se considera os calçados adequados aos pés, 13 - se já utilizou um calçado pela estética e não pelo conforto e 14 - maiores problemas percebidos em relação ao uso do calçado). Os questionários foram disponibilizados no formato físico impresso e no formato online.

$\mathrm{Na}$ sequência foi feito o levantamento antropométrico dos pés. O método apresentado foi adaptado de Manfio (1995), que utilizou procedimentos de medição direta dos pés com o uso de fita métrica. As variáveis medidas dos pés foram baseadas na NBR 15159:2013, que determina a caracterização do perímetro (medido na articulação metatarso-falangeana na seção vertical do pé sobre a linha da articulação) e comprimento (distância longitudinal entre o ponto mais proeminente na região da tuberosidade do calcâneo até o ponto mais proeminente na região da tuberosidade da falange distal). De forma adicional ao método, foi medida a numeração dos pés por meio de uma régua em ponto francês com o intuito de comparar a numeração recomenda com a numeração declarada pelas participantes. Para a medição da numeração, os pés das participantes foram posicionados em cima da régua com o calcanhar rente no seu apoio posterior (ponto mais proeminente na região da tuberosidade do calcâneo) e cursor da medida da numeração rente ao dedo mais longo do pé (ponto mais proeminente da tuberosidade da falange distal).

Os dados da coleta foram processados e analisados por meio de tratamento estatístico. As respostas do questionário foram apresentadas de acordo com a porcentagem de ocorrência. Os dados do levantamento antropométrico foram processados de acordo com as medidas das variáveis analisados pelo estudo, desse modo, são apresentados os resultados totais dos dados, a comparação dos dados das participantes com a NBR 15159:2013, a comparação entre as medidas dos pés direito e esquerdo e as médias desses dados. Na sequência, os dados da coleta foram comparados entre a percepção das participantes e o levantamento antropométrico.

\section{ETAPA 1 - FUNDAMENTAÇÃO TEÓRICA}

O capítulo da Fundamentação Teórica discorre os temas principais da pesquisa para auxiliar o desenvolvimento do estudo. São apresentadas as temáticas Calçado, Anatomia do Pé, Ergonomia e Antropometria do Pé a fim de compreender o produto de estudo (calçado) e o sistema de numeração utilizado no Brasil, os aspectos corporais dos usuários (anatomia) e os procedimentos do estudo (levantamento de dados antropométricos dos pés).

\subsection{CALÇADO}

O princípio do calçado é a proteção dos pés (CHOKLAT, 2012). No entanto problemas relacionados ao seu dimensionamento podem provocar alterações na morfologia e funcionamento (MANFIO, 1995; MENZ; LORD, 1999). Para Linden (2004), 
o uso de calçados inadequados, que oferecem risco para a saúde, ocorre diariamente e muitas vezes está associado ao uso de calçados com valores estéticos e simbólicos que pouco consideram quesitos ergonômicos. Nesse sentido, a percepção de uso do calçado está relacionada a fatores intrínsecos do produto, como as suas dimensões e características físicas, e fatores extrínsecos associados a atributos não físicos.

Dentre os fatores intrínsecos, as fôrmas relacionam-se com a percepção da adequação dimensional do calçado. A fôrma, considerada um molde tridimensional que representa o formato do calçado e dimensões anatômicas simplificadas dos pés, é o elemento base para a fabricação do calçado (ZHANG et al., 2012; LUXIMON; ZHANG, 2006). Sendo assim, o calce e modelo do calçado dependem das dimensões volumétricas da fôrma, pois ela representa as informações anatômicas dos pés (ZHANC et al., 2012).

Anteriormente à revolução industrial, os calçados eram produzidos de modo artesanal, confeccionados sob medida por sapateiros, que também desenvolviam as suas fôrmas de forma manual (SANTOS, 2017; VASS; MOLNÁR, 2015). No entanto, hoje sua fabricação é feita de modo industrial e padronizada segundo configurações dimensionais, chamadas de numerações (GOMES FILHO, 2003). As numerações têm como objetivo viabilizar economicamente a fabricação de calçados em larga escala por meio de um número limitado de tamanhos que regulamentam os valores de comprimento e perímetro de modo progressivo para cada numeração (MOLENBROEK 2000).

No mundo, os sistemas mais utilizados no mundo são o ponto inglês, o ponto francês, o ponto americano e o Mondopoint (LIGER, 2015). No entanto, o sistema utilizado no Brasil é o ponto francês que utiliza o valor de 0,66 cm (dois terços de $1 \mathrm{~cm}$ ) como medida de um ponto da numeração (SCHMIDT, 1995).

Para certificar a padronização das dimensões da fôrma conforme o sistema ponto francês, a NBR 15159:2013 (Conforto de calçados e componentes - Determinação dos diferentes perfis para o mesmo número - Fôrmas), estabelece o comprimento perímetro das fôrmas para cada numeração em relação ao comprimento total dos pés e perímetros. Neste sentido, de acordo com o estudo antropométrico de Domingues (2016), feito com os pés da população feminina de Campina Grande - PB, foi identificado uma variação de perímetro da articulação metatarso-falangeana dos brasileiros em relação às medidas estabelecidas pela NBR 15159:2013, totalizando o acréscimo de dois pontos da numeração nesta região. Para Domingues (2016), as fôrmas de calçados no Brasil podem não corresponder ao tamanho dos pés da população feminina brasileira, mesmo para aquelas que não possuem problemas estruturais nos pés, como deformações por exemplo.

Segundo Xiong e Zhao (2013) e Goldcher (2009), o dimensionamento inadequado do calçado nos pés pode causar problemas clínicos como bolhas, dores, deformações e ulcerações. Portanto, estima-se que o desenvolvimento de calçados que atendam mais adequadamente o perfil anatômico dos pés pode determinar o bom calce e conforto para a população.

\subsection{ANATOMIA DO PÉ}

Entender a anatomia é essencial na compreensão do formato e funcionamento dos pés para o desenvolvimento de calçados mais adequados para os usuários (XIONG; ZHAO, 2013; LUXIMON; LUXIMON, 2012). O pé contribui significativamente para o funcionamento do membro inferior, suportando o peso do corpo durante a locomoção e posição ereta.

De modo geral, o pé é composto de uma estrutura de 26 ossos, 33 articulações músculos, tendões, ligamentos, vasos sanguíneos, nervos, pele e tecidos (HAMILL; KNUTZEN; DERRICK, 2015). Dentre os ossos, o pé possui 7 tarsais, 5 metatarsais e 14 falanges em sua estrutura. Os ossos tarsais compreendem o conjunto do calcâneo, tálus, cuboide, navicular e três ossos cuneiformes. Os metatarsais I, II, III, IV e V possuem a base articuladas com os cuneiformes, cuboide e falanges proximais e são numerados a partir do lado medial do pé. Por sua vez, as falanges formam os dedos do pé, sendo que cada dedo possui três falanges, com exceção do dedão, que possui apenas duas (MOORE; DALLEY, 2006).

O pé pode ser dividido em três regiões (Figura 2) compreendidas por: retropé composto do táluse do calcâneo; mediopé, composto dos ossos navicular, cuneiformese cubóide; e antepé, composto dos metatarsais e falanges (HAMILL; KNUTZEN; DERRICK 2015).

Figura 2: Regiões dos pés com base em Hamill, Knutzen e Derrick (2015)

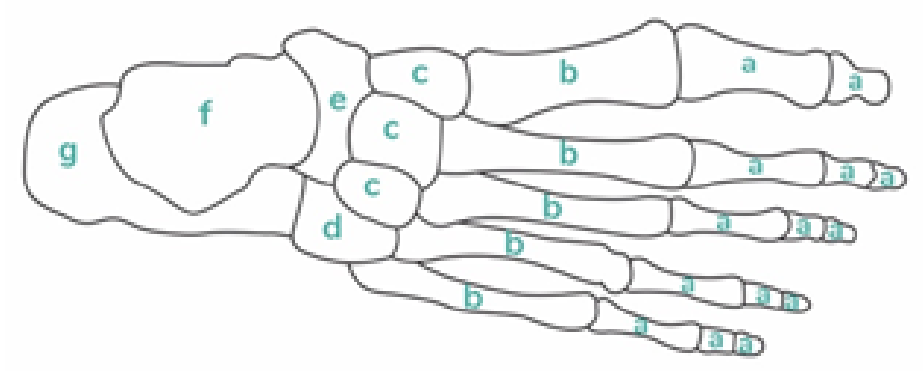

ANTEPE MEDIOPE (d) Cuboide (e) Navicular RETROPÉ (f) Tálus (g) Calcâneo

Fonte: Os autores

O pé também é composto de três arcos formados pelos ossos tarsais e metatarsais (Figura 3). Estes arcos compõem um sistema funcional dos pés para a transmissão do peso corporal, amortecimento do choque do pé com o solo e suavização da marcha (HAMILL; KNUTZEN; DERRICK, 2015).

Figura 3: Arcos plantares com base em Hamill, Knutzen e Derrick (2015)
ARCO TRANSVERSO

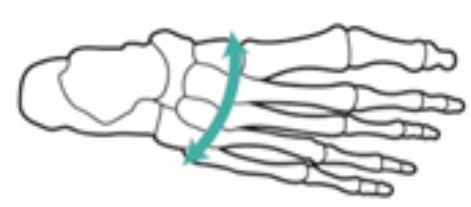

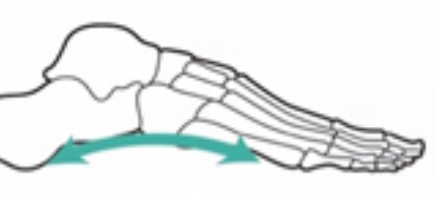

ARCO LONGITUDINAL LATERAL

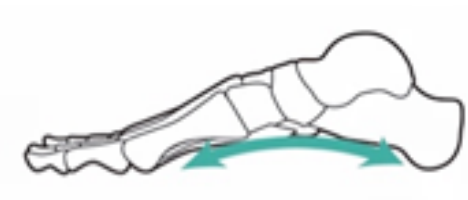

MEDIAL
ARCO LONGITUDINAL

Fonte: Os autores

O arco transverso composto pelos ossos tarsais e base dos ossos metatarsais está relacionado a largura dos pés. Sua capacidade de sustentar o peso corporal faz com que o arco seja aplainado quando em contato com o chão, espalhando a região do 
antepé (HAMILL; KNUTZEN; DERRICK, 2015).

Os arcos longitudinais lateral e medial compõem a configuração dos pés relacionada ao comprimento. $O$ arco longitudinal lateral é composto pelos ossos calcâneo, cuboide, IV metatarso e V metatarso. Possui mobilidade limitada por estar mais em contato com o solo e sua configuração é relativamente plana. Já o arco longitudinal medial é configurado pelos ossos do calcâneo, tálus, navicular, cuneiformes e os três primeiros metatarsos (I, II e III). Apresenta maior flexibilidade, absorve os impactos do pé com o solo e a sua altura determina os tipos de pé: normal, de arco alto ou pé cavo, e plano ou pé chato (HAMILL; KNUTZEN; DERRICK, 2015).

De modo geral, estas estruturas dos pés podes sofrer variações conforme a idade, suporte de carga corporal, sexo, ambiente e etnia (XIONG; ZHAO, 2013). Nesse sentido, para Xiong e Zhao (2013), com o aumento da idade, a largura dos pés aumenta; com o aumento do peso corporal os pés ficam mais longos, mais largos e com menor altura; os pés femininos geralmente possuem formas mais delgadas e menores que os pés masculinos; os fatores ambientais como estado de nutrição calor e umidade também pode modificar as dimensões dos pés, para adequá-las ao ambiente que o usuário está inserido; do mesmo modo, a origem étnica também interfere na anatomia dos pés, po exemplo, é observado que o pé escocês é largo, chato e com ossos proeminente, o pé irlandês é pequeno e mais gordo e o pé francês é mais longo e possui maiores arcos plantares.

\subsection{ERGONOMIA E ANTROPOMETRIA DO PÉ}

A ergonomia pode ser entendida como "uma disciplina científica que estuda as interações dos homens com outros elementos do sistema" (IEA, 2018). Para isso, emprega os conhecimentos de outras áreas científicas como antropometria, a biomecânica e a psicologia para a solução de problemas sociais relacionados à saúde, conforto, eficiência e segurança (DUL; WEERDMEESTER, 2012).

A antropometria, portanto, é um ramo da ergonomia que estuda as dimensões do corpo humano (DUL; WEERDMEESTER, 2012). De modo padronizado, as medidas antropométricas podem ser feitas de forma direta ou indireta. As formas diretas de medição envolvem instrumentos que medem diretamente as dimensões dos pés como réguas, paquímetros e fitas métricas. Já as formas indiretas são feitas com equipamentos que medem indiretamente as dimensões do corpo como o scanner 3D, que emprega a varredura a laser para digitalizar partes do corpo de forma tridimensional (XIONG ZHAO, 2013).

A antropometria para a confecção de calçados envolve a medição dos pés com o intuito de desenvolver produtos ergonomicamente adequados (XIONG; ZHAO, 2013). De forma geral, as medidas utilizadas para a fabricação de calçados envolvem o comprimento do pé e medidas circulares de perímetro que determinam a largura e volume do calçado (HINOJO-PÉREZ et al., 2015).

Para isso, o dimensionamento do pé é caracterizado na fôrma do calçado. Conforme a NBR 15159:2013, o padrão de fôrmas brasileiras utiliza medidas de comprimento estabelecida pelo ponto francês e medidas de perímetros, sendo que apenas o perímetro da fôrma na região metatarso-falangeana possui as definições de parâmetros utilizados para o seu dimensionamento.

O comprimento do pé, de acordo com a NBR 15159:2013, é entendido como a "distância longitudinal entre o ponto mais proeminente na região da tuberosidade do calcâneo até o ponto mais proeminente na região da tuberosidade da falange distal do dedo mais saliente (dedo I, dedo II ou dedo III)". Para a medição do comprimento pela forma direta podem ser utilizados a fita métrica (VASS; MOLNÁR, 2015), o paquímetro (MENIN, 2009), o micrômetro (MANFIO, 1995) e as réguas de medição da numeração dos pés, como exemplo o Dispositivo de Brannock, utilizado nos Estados Unidos.

Já o perímetro dos pés, segundo a NBR 15159:2013, é entendido como "perímetro medido na articulação metatarso-falangeana na seção vertical do pé sobre a linha da articulação". Das formas diretas de medicãa, o uso de fitas métricas pode ser utilizado para o dimensionamento do perímetro dos pés (VASS; MOLNÁR, 2015).

\section{ETAPA 2 - COLETA DE DADOS}

Neste capítulo é apresentado os resultados das coletas respectivas ao levantamento de dados demográficos pelo questionário de percepção de uso do calçado e levantamento de dados antropométricos pela medição direta da numeração dos pé e variáveis de perímetro da articulação metatarso-falangeana.

O estudo aconteceu entre os dias 20 e 21 de setembro de 2018 no pátio da Universidade do Sagrado Coração, em Bauru - SP, no II CBTA: Congresso Brasileiro de Pesquisa e Desenvolvimento em Tecnologia Assistiva: Engenharia e Design. A seleção da amostra de 14 participantes do sexo feminino ocorreu por conveniência e ao todo foram coletados dados antropométricos de 28 pés.

Os resultados a seguir são divididos em 3 partes: Questionário de uso e percepção dos calçados (1), Levantamento antropométrico dos pés (2) e Análise dos dados (3), onde são comparados os dados qualitativos do questionário com os dados quantitativos do levantamento antropométrico, fazendo a relação com a norma NBR 15159:2013, em relação ao seu perfil médio para fôrmas de calçados femininos.

\subsection{QUESTIONÁRIO DE USO E PERCEPÇÃO DOS CALÇADOS}

A fim de entender a percepção geral de uso dos calçados foi aplicado um questionário, com base em Manfio (1995) e Menin (2009), composto de 14 perguntas divididas em 2 tópicos: tópico 1 - dados de identificação e tópico 2 - dados sobre a percepção de uso dos calçados. O questionário foi respondido por uma amostra composta de 14 participantes do sexo feminino. A idade variou de 18 a 47 anos, sendo que a média foi 30,7 anos.

O tópico 1 das perguntas do questionário envolveu questões sobre a identificação das participantes. Tendo em vista a participação de pessoas de várias partes do Brasil no evento, uma das perguntas do questionário foi em relação a sua cidade e estado de proveniência, a fim de identificar as localidades das participantes. O resultado apresentou uma grande porcentagem de participantes de Bauru-SP (57,2\%), cidade que sediou o congresso, seguido por $21,4 \%$ das participantes de Florianópolis-SC, $14,3 \%$ de Curitiba-PR e $7,1 \%$ de Recife-PE, provavelmente relacionados às instituições de ensino que participaram do congresso. $O$ resultado das cidades provenientes das participantes é ilustrado na Figura 4. 
Figura 4: Cidade e estado das participantes

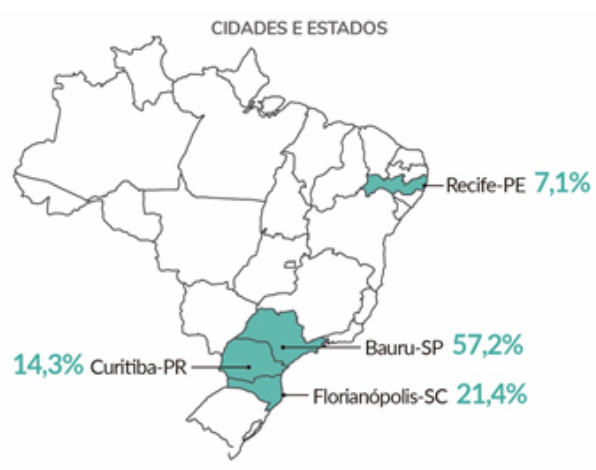

Fonte: Os autores

A descendência das participantes foi questionada a fim de identificar padrões em relação ao perfil dimensional, segundo Xiong e Zhao (2013), questões étnicas apresentam contribuição para o formato dos pés. Dentre as participantes da pesquisa 40,9\% declararam apresentar descendência italiana, 13,8\% portuguesa, 13,8\% indígena, 4,5\% alemã, 4,5\% brasileira, 4,5\% austríaca, 4,5\% romena, 4,5\% afrodescendente, 4,5\% espanhola e 4,5\% europeia. Por estes resultados, percebe-se a alta incidência de descendências de origem europeia (italiana, portuguesa, alemã, austríaca, romena e espanhola), totalizando $77,3 \%$ das participantes.

Quando questionados sobre a presença de problemas de saúde, a fim de identificar patologias que poderiam interferir no uso de calçados, $28,6 \%$ da amostra declarou que não possuem problemas de saúde. Entre a porcentagem que declarou possuir problemas de saúde $(71,4 \%)$ estacou-se a presença de lordose, escoliose, tireoide e psoríase.

No tópico 2, foram questionados aspectos relacionados a percepção de uso dos calçados. As participantes declararam a numeração de calçado que mais usavam, a fim de comparar os resultados com a numeração indicada pela régua de calce, na coleta de dados antropométricos. Nesse sentido, as numerações variaram do 34 ao 38 , sendo que a média foi de 36,5 pontos.

No intuito de compreender a presença de dores nos pés, foi questionada as regiões de maior desconforto. O resultado (Figura 5) mostrou que a região do metatarso foi a mais comentada como área de desconforto $(33,3 \%)$, seguido pelos dedos do pé $(29,2 \%)$ calcanhar (25\%) e arco plantar longitudinal lateral (12,5\%).

Figura 5: Regiões de desconforto dos pés das participantes REGIÕES DE DESCONFORTO DOS PÉS

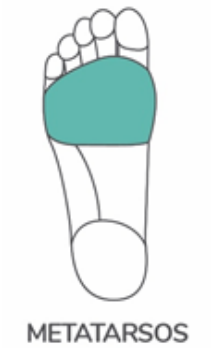$$
33,3 \%
$$
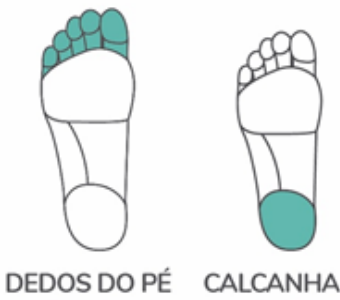

$29,2 \%$

Fonte: Os autores
Quando questionados sobre os modelos de calçado mais utilizados (Figura 6) das opções de escolha (tênis, sapatilha, chinelo, bota, rasteirinha, alpargata, oxford, mocassim, sandália, mule, scarpin, espadrille e tamanco), a sapatilha $(23,4 \%)$, o tênis $(19,1 \%)$, o chinelo $(10,6 \%)$, a bota $(10,6 \%)$ e a rasteirinha $(10,6 \%)$ apresentaram maior pontuação.

Figura 6: Modelos de calçados mais usados

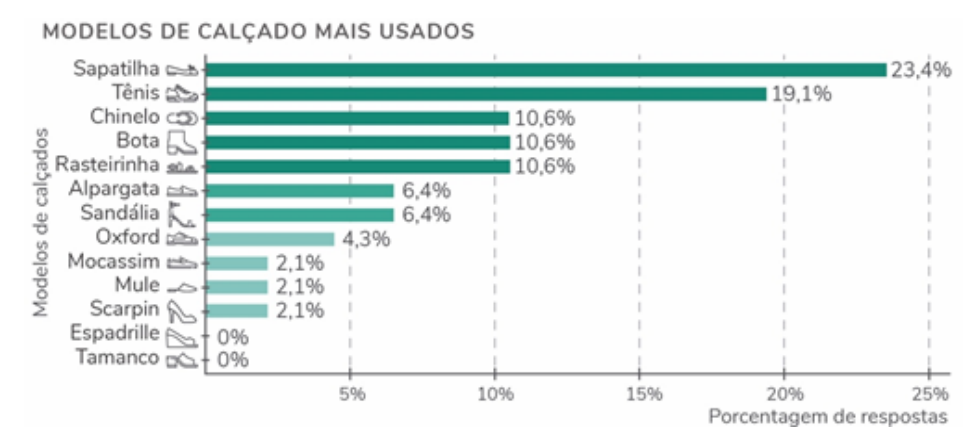

Fonte: Os autores

Já os calçados que apresentam maior conforto (Figura 7), dentre as mesmas opções de modelo, foram o tênis $(25,9 \%)$, o chinelo $(22,2 \%)$, a alpargata $(11,1 \%)$ e a sapatilha $(11,1 \%)$.

Figura 7: Modelos de calçados com mais conforto

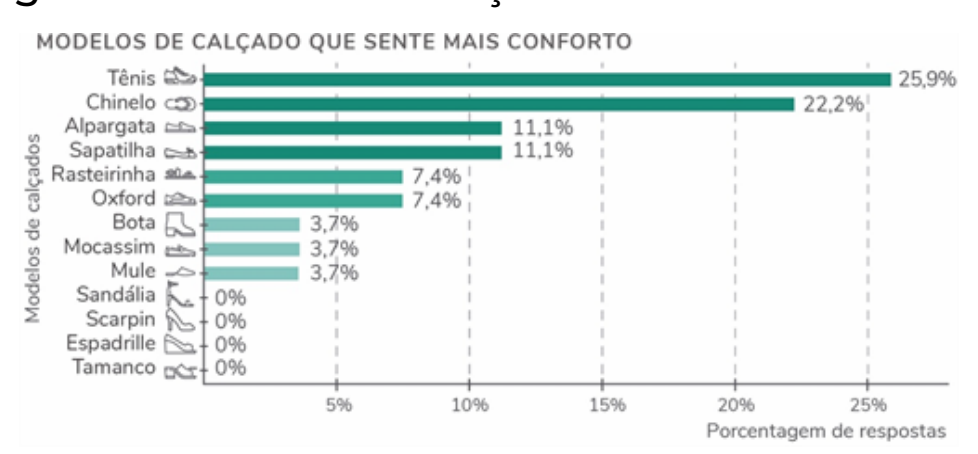

Fonte: Os autores

Do mesmo modo, foi questionado os modelos de calçado que apresentam maior desconforto (Figura 8), nesse quesito os modelos mais desconfortáveis foram o scarpin $(31,4 \%)$, a sandália $(28,6 \%)$ e a bota $(11,4 \%)$. 
Figura 8: Modelos de calçados com mais desconforto

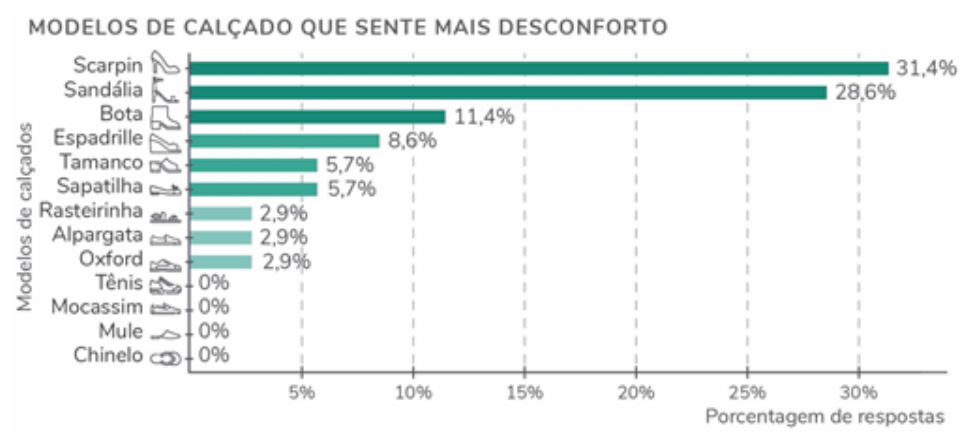

Fonte: Os autores

A frequência de uso de calçados de salto alto foi questionada a fim de analisar a percepção de risco à saúde referente a este modelo de calçado, como estudado em Linden (2004). Nesse sentido, 57,1\% das participantes relataram usar calçado de salto alto raramente, $28,6 \%$ ocasionalmente (1 vez por semana) e 14,3\% frequentemente ( 2 a 3 vezes por semana).

Cerca de $\mathbf{8 5 , 7 \%}$ da amostra considerou que os calçados não eram adequados para os seus pés relatando problemas de aperto, bolhas, dores e assimetria dos pés, que dificulta a escolha de calçados que sejam adequados para ambos os membros. A relação do uso de calçados pela estética sem considerar o conforto também foi questionada a fim de levantar a percepção de risco de uso de calçados desconfortáveis fisicamente perante o conforto psicológico, relacionado a estética. Nesse sentido, 85,7\% já usaram calçados pela estética e não pelo conforto, sendo as razões dessa escolha foram relacionadas ao uso em ocasiões de festas e eventos.

Quando questionados sobre os maiores problemas percebidos em relação ao uso de calçados, as reclamações relacionaram-se a dores nas regiões da panturrilha, calcanhar e sola do pé; bolhas; falta de numerações quebradas; preço; e modelos que apertam os pés.

\subsection{LEVANTAMENTO ANTROPOMÉTRICO DOS PÉS}

Foi aplicado um levantamento antropométrico em 28 pés (pés direito e esquerdo das 14 mulheres participantes da amostra). A coleta seguiu a ordem dos procedimentos: medição do pé com a régua (em ponto francês), a fim de comparar a numeração declarada pelas participantes com a numeração recomendada pela régua, e medição do perímetro da cabeça dos metatarsos com a fita métrica. As medidas foram comparadas com a NBR15159:2013 para o perfil médio de fôrmas de calçados femininos, sendo que as numerações dos pés utilizadas para essa comparação foram as numerações recomendadas pela régua, pois possui dados mais precisos sobre o número de calce de cada pés e a inclusão de numerações quebradas.

\subsubsection{NUMERAÇÃO DOS PÉS}

As numerações medidas pela régua no pé direito variaram do número 34 ao 39 sendo que a média foi de 37,5 pontos. Já as numerações pela régua no pé esquerdo foram do 33,5 e 39, com média de 37,3 pontos. Como comparação entre as médias dos pés, observou-se que o pé direito possuiu comprimento maior que o pé esquerdo, de acordo com as pontuações do sistema de medidas.

A diferença entre a numeração declarada menos a numeração pela régua para o pé direito (Figura 9) variou de -2 pontos à 0,5 pontos da numeração, sendo que a pontuação negativa significa que a numeração declarada foi menor que a numeração do pé conforme a régua. As maiores variações, nesse caso, foram de -2 pontos (21,43\%), -1 ponto $(42,86 \%)$ e $-0,5$ ponto $(14,29 \%)$, com média de -1 ponto. Observou-se que na maior parte dos casos a numeração recomendada pela régua para o pé direito foi maior que a numeração utilizada pelas participantes, indicando assim um possível uso de calçados mais apertados.

Figura 9: Numeração declarada menos a numeração pela régua - pé direito

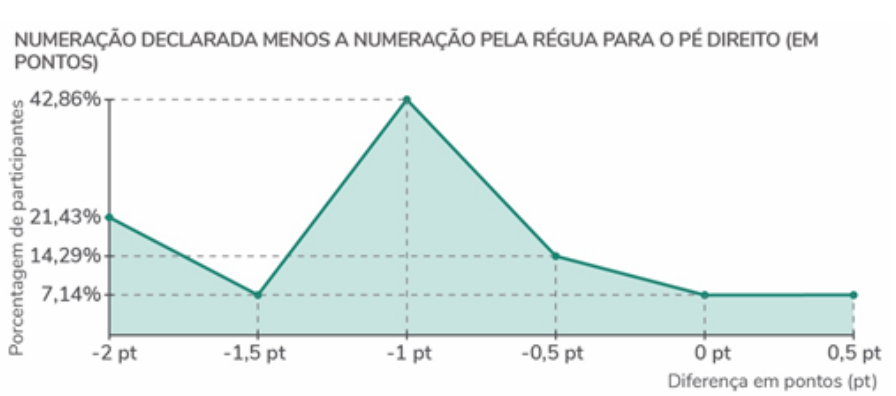

Fonte: Os autores

Para o pé esquerdo, a diferença entre a numeração declarada menos a numeração pela régua variou de -2 pontos à 0,5 ponto (Figura 10), sendo que as maiores variações foram de -2 pontos $(14,29 \%),-1,5$ ponto $(14,29 \%),-1$ ponto $(28,57 \%)$ e 0 pontos $(28,57 \%)$ indicando que em grande parte dos casos a numeração declarada foi menor ou igual a numeração recomendada pela régua (diferença de 0 pontos). A média da diferença entre a numeração da régua e declarada pelas participantes para o pé esquerdo foi de $-0,78$ pontos.

Figura 10: Numeração declarada menos a numeração pela régua - pé esquerdo

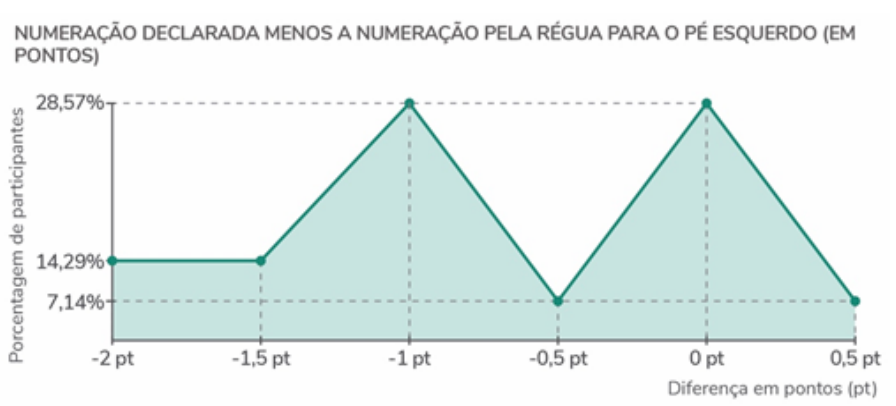

Fonte: Os autores

Quando comparada a numeração do pé direito com a numeração do pé esquerdo pela régua em pontos (Figura 11), 14,29\% da amostra apresentou -0,5 pontos de diferença o que representa que o pé direito era menor que o pé esquerdo e $35,7 \%$ tinham o pé direito e o esquerdo com a mesma numeração. Já as participantes que apresentaram o 
pé direito maior que o esquerdo possuíam a diferença de 0,5 pontos $(42,86 \%)$ e 1 ponto (7,14\%). Nesse cenário, percebe-se que em mais da metade das participantes, o pé direito apresentou numeração maior que o pé esquerdo, mostrando assim a assimetria dos membros inferiores e a dificuldade em encontrar calçados adequados que atendam membros inferiores e a dificuldade em encontrar calçados adequados que atendam a falta de numerações quebradas (GOMES FILHO, 2003) que fazem com que o usuário opte por comprar dois pares de calçado, cada um com numeração adequada para um dos pés, ou acabe optando por usar um calçado que fique mais apertado em um dos pés que no outro.

Figura 11: Numeração do pé direito menos a numeração do pé esquerdo

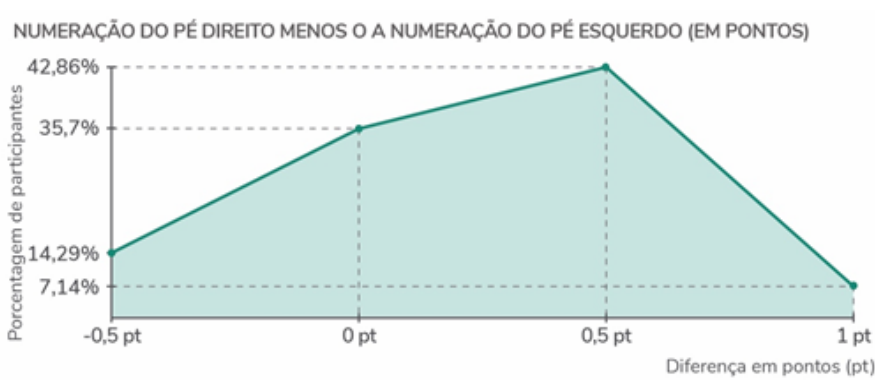

Fonte: Os autores

\subsubsection{PERÍMETRO DOS METATARSOS}

O perímetro dos metatarsos do pé direito (Figura 12) em 12 participantes $(85,7 \%$ da amostra) apresentou tamanho maior em comparação com as mesmas dimensões do perímetro do metatarso da NBR 15158:2013. A diferença dimensional entra a NBR 15159:2013 e o perímetro dos metatarsos das participantes foi de $-3 \mathrm{~cm}$ a $-0,5 \mathrm{~cm}$, sendo que a pontuação negativa representa que as dimensões da norma são menores que 0 perímetro das participantes. A média das diferenças foi de $-1 \mathrm{~cm}$.

Figura 12: Perímetro dos metatarsos da norma menos o perímetro dos metatarsos das participantes - pé direito

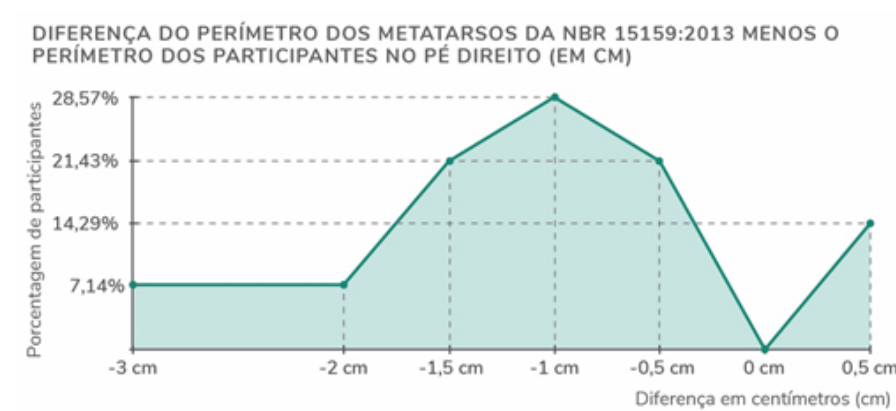

Fonte: Os autores

Do mesmo modo, o perímetro dos metatarsos da NBR 15158:2013 menos os perímetros medidos nos pés esquerdos (Figura 13) apresentaram medidas negativas em $71,4 \%$ das participantes, indicando que a norma possui dimensões menores em mais da metade da amostra. As diferenças dimensionais entre a norma e o perímetro da amostra para o pé esquerdo foram de $-2 \mathrm{~cm}$ a $-0,5 \mathrm{~cm}$, com média de $-0,67 \mathrm{~cm}$.
Figura 13: Perímetro dos metatarsos da norma menos o perímetro dos metatarsos das participantes - pé esquerdo

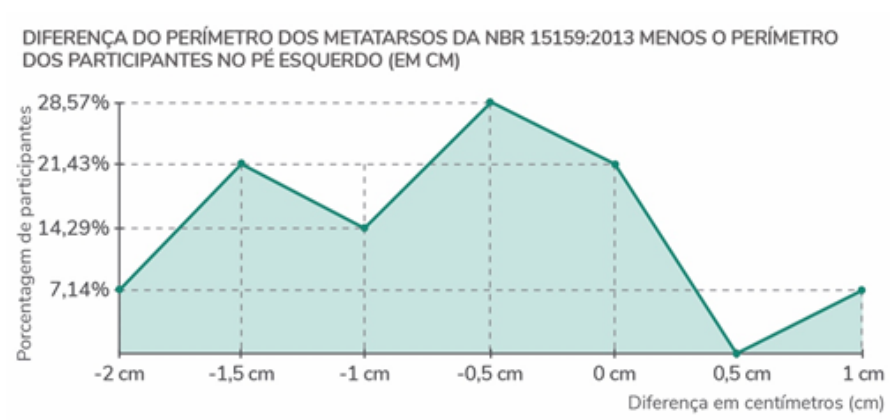

Fonte: Os autores

O perímetro do metatarso do pé direito e do pé esquerdo (Figura 14) apresenta diferença dimensional de $0,5 \mathrm{~cm}$ em $50 \%, 1 \mathrm{~cm}$ em $7,14 \%$ e $1,5 \mathrm{~cm}$ em $7,14 \%$ da amostra, com média de $0,21 \mathrm{~cm}$. Nesse sentido, é possível notar que o perímetro do metatarso do pé direito foi maior que o do pé esquerdo em 71,4\% da amostra, apresentando que o pé direito além de mais comprido apresenta maior largura no metatarso.

Figura 14: Diferença entre o perímetro dos metatarsos do pé direto menos o pé esquerdo

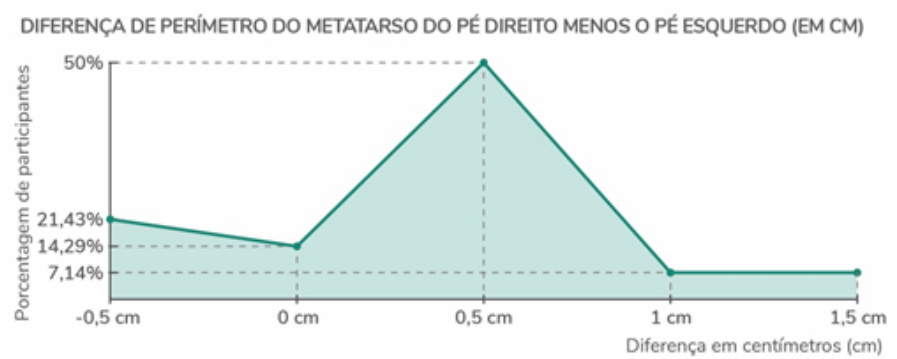

Fonte: Os autores

\subsection{ANÁLISE DOS DADOS}

A análise dos dados foi feita pela comparação dos tópicos do questionário relacionado à percepção de uso do calçado (regiões de desconforto, modelos de calçado mais usados, modelos de calçado com mais conforto, modelos de calçado com mais desconforto, frequência de uso de salto alto, adequação do calçado nos pés, uso do calçado pela estética e problemas de uso do calçado), a numeração (declarada e recomendada) e o perímetro dos pés (das participantes e da NBR 15159:2013). Os itens analisados foram agrupados conforme a suas possíveis relações e interferências na estrutura dos pés, percepção e escolha de uso. Desse modo, os itens foram divididos em: perímetro do metatarso e região de desconforto; modelos de calçado; frequência de uso de salto alto, estética e regiões de desconforto; e numerações, adequação do calçado e problemas nos pés. 


\section{-Perímetro do metatarso e região de desconforto}

O perímetro do metatarso relaciona-se com a região de desconforto uma vez que $33,3 \%$ das participantes relataram apresentar desconforto na região do metatarso. Desse modo, o levantamento antropométrico do perímetro do metatarso, mostrou a possível inadequação da norma com a amostra, sendo que 85,7\% das participantes apresentou - perímetro de seus metatarsos do pé direito maior que o dimensionamento da NBR 15159:2013 e 71,4\% para o pé esquerdo. Nesse sentido, o uso de calçados apertados na região dos metatarsos pode desenvolver lesões e deformações nos pés, como o hálux valgo, por exemplo, caracterizado pelo desalinhamento do primeiro metatarso no grande dedo do pé que pode ser causado pelo uso de calçados estreitos (GOLDCHER, 2009).

\section{-Modelos de calçado}

Pelo resultado do questionário, foi possível perceber a relação entre os calçados mais usados e os calçados percebidos como mais confortáveis. Dentre os modelos mais escolhidos nesse quesito destacam-se o tênis, o chinelo e a sapatilha. Por outro lado, os modelos que apresentam mais desconforto foram declarados como usados com menor frequência. Dentre as opções de modelos a sandália e o scarpin foram mencionados como os mais desconfortáveis, e apresentaram nenhum voto como calçado confortável, apresentando assim coerência entre as respostas das participantes.

\section{-Frequência de uso de salto alto, estética e regiões de desconforto}

O uso de salto alto foi relatado como raro em $57,1 \%$ das participantes, ocasional em $28,6 \%$ e frequente em $14,3 \%$. Esses dados podem ser relacionados ao uso de calçados pela estética desconsiderando o conforto (85,7\%), uma vez que as razões de seu uso envolvem ocasiões de festas e eventos. Nesse sentido o uso de salto alto pode ser visto como um valor simbólico que o torna uma obrigação social em eventos formais principalmente para o sexo feminino (LINDEN, 2004). Por sua vez, o uso de salto alto interfere principalmente na região do metatarso, uma vez que aumenta a pressão máxima na cabeça do primeiro metatarso, podendo causar dores, deformações e ulcerações no pé (GOLDCHER, 2009).

\section{- Numerações, adequação do calçado e problemas nos pés}

A assimetria dos pés, representada pelo pé direito ser maior que o pé esquerdo, e a falta de numerações quebradas, mencionada no resultado do questionário e vista em Gomes Filho (2003) como um dos fatores de problemas de adaptação dos calçados nos pés, também pode ser um fator que estimula o uso de calçados inadequados, por forçar a escolha de uma numeração maior ou menor que o tamanho ideal. As diferenças dimensionais entre a numeração declarada e a numeração recomenda apresenta que $50 \%$ das participantes utilizam calçados mais apertados no pé direito e $35,7 \%$ no pé esquerdo. Nesse sentido, o uso de calçados apertados pode estar relacionado aos resultados do questionário, que apresenta como problemas comuns a presença de dores no calcanhar e sola do pé, bolhas e desconforto nas regiões dos dedos dos pés, calcanhar e arco plantar longitudinal lateral.

\section{CONSIDERAÇÕES FINAIS}

Calçados mais adequados para o perfil da população brasileira podem contribuir para o desenvolvimento de pés saudáveis. Para tanto, o uso de normas e padrões de medidas para a fabricação de calçados deve estar adequado às dimensões dos pés como forma de determinar o bom calce e conforto.

O estudo aplicou um questionário sobre a percepção de uso do calçado e levantou dados antropométricos dos pés de uma amostra de 14 participantes. As questões relacionadas a percepção de uso do calçado, pela coleta de dados com a aplicação do questionário, apresentaram a presenças de desconforto e problemas nos pés que podem estar relacionados com o uso de calçados com dimensionamento inadequado. Por sua vez, o levantamento antropométrico dos pés refletiu a possível falta de adequação da NBR 15159:2013 com a amostra, que apresentou discrepâncias em relação ao perímetro dos pés das participantes.

Pelo estudo, os modelos de calçados com mais desconforto e menor frequência de uso podem servir de base para futuros projetos de calçados que melhorem a sua ergonomia promovendo maior saúde para os usuários, principalmente em calçados de salto alto.

De igual forma, destaca-se o uso combinado de tipos de medição direta, como o instrumento da fita métrica utilizada no presente estudo, e medição indireta como o uso do scanner 3D, como forma de contribuir para a aferição das medidas dos pés.

O estudo contribuiu para investigar de modo preliminar algumas questões relacionadas a norma que padroniza o dimensionamento de calçados no Brasil. No entanto, ressalta-se a necessidade de estudar de forma mais aprofundada o levantamento antropométrico com um maior número de variáveis medidas dos pés e uma amostragem representativa da população feminina e masculina no Brasil.

\section{AGRADECIMENTOS}

Agradecemos à Coordenação de Aperfeiçoamento de Pessoal de Nível Superior (CAPES), ao Programa de Pós Graduação em Design da Universidade Federal de Santa Catarina (UFSC), ao Núcleo de Gestão de Design (NGD) \& Laboratório de Design e Usabilidade (LDU) e à Rede de Pesquisa de Pesquisa e Desenvolvimento em Tecnologia Assistiva (RPDTA) por viabilizarem o presente estudo. 


\section{REFERÊNCIAS}

ASSOCIAÇÃO BRASILEIRA DE NORMAS TÉCNICAS. NBR 15159: conforto de calçados componentes - Determinação dos diferentes perfis para o mesmo número - Fôrmas. Rio de Janeiro, jul. 2013.

CHOKLAT, Aki. Design de Sapatos. São Paulo: Senac, 2012.

DOMINGUES, Carolina Ângelo Jerônimo. Estudo Da Influência Das Dimensões Dos Metatarsos No Conforto Dos Calçados Femininos: O Caso Da Cidade De Campina Grande, PB. 2016. 123 f. Dissertação (Mestrado) - Curso de Design, Universidade Federal de Campina Grande, Campina Grande, 2016.

DUL, Jan; WEERDMEESTER, Bernard. Ergonomia Prática. São Paulo: Blucher, 2012.

GOLDCHER, Alain. Podologia. 5. ed. São Paulo: Roca, 2009.

GOMES FILHO, João. Ergonomia do Objeto: Sistema Técnico de Leitura Ergonômica. São Paulo: Escrituras Editora, 2003.

HAMILL, Joseph; KNUTZEN, Kathleen M.; DERRICK, Timothy R.. Biomechanical Basis of Human Movement. 4. ed. Filadélfia: Wolters Kluwer, 2015.

HINOJO-PÉREZ, Juan José et al. Automation of the shoe last grading process according to international sizing systems. The International Journal Of Advanced Manufacturing Technology, [s.l.], v. 85, n. 1-4, p.455-467, 15 out. 2015. Springer Nature. http://dx.doi. org/10.1007/s00170-015-7947-8.

INTERNATIONAL ERGONOMICS ASSOCIATION. Definition and Domains of Ergonomics. Disponível em: <https://www.iea.cc/whats/index.html>. Acesso em: 3 nov. 2018.

LIGER, Ilce. Modelagem de Calçados: Técnicas e Passo A Passo. São Paulo: Senac, 2015.

LINDEN, Júlio Carlos de Souza van Der. Um Modelo Descritivo Da Percepção De Conforto E De Risco Em Calçados Femininos. 2004. 412 f. Tese (Doutorado) - Curso de Engenharia de Produção, Universidade Federal do Rio Grande do Sul, Porto Alegre, 2004.

LUXIMON, Ameersing; ZHANG, Ming. Shoe Last Design for Improved Fit and Comfort. In: KARWOWSKI, Waldemar (Ed.). International Encyclopedia of Ergonomics and Human Factors. 2. ed. Kentucky: Taylor \& Francis Group, 2006. Cap. 6. p. 1707-1711.

LUXIMON, Ameersing; LUXIMON, Yan. Shoe-Last Design and Development. In: GOONETILLEKE, Ravindra S. (Ed.). The Science of Footwear. Boca Raton: Crc Press, 2012. p. 193-212. (Human Factors and Ergonomics).

MANFIO, Eliane Fátima. Estudo de Parâmetros Antropométricos e Biomecânicos do Pé Humano Para a Fabricação de Calçados Segundo Critérios de Conforto, Saúde e Segurança. 1995.127 f. Dissertação (Mestrado) - Curso de Ciência do Movimento Humano, Universidade Federal de Santa Maria, Santa Maria, 1995.

MENIN, Mariana. Antropometria das Extremidades dos Membros Inferiores de Obesos: Parâmetros para o Design Ergonômico de Calçados. 2009. 86 f. Dissertação (Mestrado) - Curso de Design, Universidade Estadual Paulista, Bauru, 2009.

MENZ, Hylton B.; LORD, Stephen R. Foot problems, functional impairment, and falls in older people. Journal Of The American Podiatric Medical Association, [s.l.], v. 89, n. 9, p.458-467, set. 1999. American Podiatric Medical Association. http://dx.doi. org/10.7547/87507315-89-9-458.

MOLENBROEK, Johan F.M.. Making an Anthropometric Size System Interactively. Proceedings OfTheHuman FactorsAnd Ergonomics SocietyAnnual Meeting, [s.l.] v. 44, n . 38, p.766-769, jul. 2000. SAGE Publications. http://dx.doi.org/10.1177/154193120004403822.

MOORE, Keith L.; DALLEY, Arthur F.. Anatomia Orientada Para A Clínica. 4. ed. São Paulo: Guanabara Koogan, 2006.

SANTOS, David Bastida. Um Padrão Antropométrico Para As Empresas De Calçados De Campina Grande Baseado Em Medidas Específicas Das Mulheres Idosas. 2017. 108 f. Dissertação (Mestrado) - Curso de Design, Universidade Federal de Campina Grande, Campina Grande, 2017.

SCHMIDT, Mauri Rubem. Modelagem Técnica de Calçados. Porto Alegre: Serviço Nacional de Aprendizagem Industrial, 1995.

SILVA, Edna Lúcia da; MENEZES, Estera Muszkat. Metodologia da Pesquisa e Elaboração de Dissertação. Florianópolis: UFSC, 2005.

VASS, László; MOLNÁR, Magda. Handmade Shoes for Men. Slovenia: H F Ullmann, 2015.

WITANA, Channa P; FENG, Jiejian; GOONETILLEKE, Ravindra S. Dimensional differences for evaluating the quality of footwear fit. Ergonomics, [s.I.], v. 47, n. 12, p.1301-1317, 10 out. 2004. Informa UK Limited. http://dx.doi.org/10.1080/00140130410001712645.

XIONG, Shuping; ZHAO, Jianhui. Foot models and measurements. In: LUXIMON, A. (Ed.) Handbook of Footwear Design and Manufacture. Filadélfia: Woodhead Publishing, 2013. p. 72-89.

ZHANG, Yifan et al. Shoe-last design exploration and customization. The Journal Of The Textile Institute. Hong Kong, p. 541-548. 2012 